\title{
Educação inclusiva e formação de professores: desafios e perspectivas a partir do Pacto Nacional pela Alfabetização na Idade Certa
}

\author{
Inclusive education and continuous teacher \\ education: challenges and perspectives from the \\ National Pact for Literacy at the Right Age
}

\section{Educación inclusiva y formación docente: desafíos y perspectivas a partir del Pacto por la Alfabetización Nacional en la Edad Apropiada}

\author{
Helenise Sangoi Antunes* \\ Andréia Jaqueline Devalle Rech ${ }^{* *}$ \\ Cínthia Cardona de Ávila**
}

Resumo: Este artigo tem como finalidade discutir a respeito da formação de professores sob o viés da perspectiva da Educação Inclusiva. São analisadas as contribuições de um programa de formação de professores frente à sua prática pedagógica junto aos alunos com deficiência. Para tanto, realizou-se uma pesquisa em que os professores Orientadores de Estudo, participantes do Pacto Nacional pela Alfabetização na Idade Certa (PNAIC), do Rio Grande do Sul, refletiram sobre as possíveis contribuições desse programa para com suas práticas pedagógicas frente aos alunos com deficiência. Diante disso, 347 Orientadores de Estudo responderam a uma entrevista estruturada, em que se constatou que o PNAIC contribuiu com a prática pedagógica inclusiva de $74,06 \%$ desses professores. Além disso, para 95,1\% deles, o PNAIC contribuiu como um programa de formação continuada qualificando suas práticas pedagógicas. Acreditase, portanto, que o PNAIC colaborou para ressignificar a prática pedagógica de muitos professores, além de oportunizar uma formação, ainda que incipiente, sobre a Educação Inclusiva.

Palavras-chave: Educação Inclusiva. Formação de professores. Pacto Nacional pela Alfabetização na Idade Certa.

\footnotetext{
*Professora da Universidade Federal de Santa Maria (UFSM). Email: <professora@helenise.com.br>

** Doutoranda em Educação - Programa de Pós-Graduação em Educação da Universidade Federal de Santa Maria (UFSM). E-mail: <prof.andirech@gmail.com>

*** Doutoranda em Educação - Programa de Pós-Graduação em Educação da Universidade Federal de Santa Maria (UFSM). E-mail: <cinthysm@yahoo.com.br>
} 


\begin{abstract}
This paper aims to discuss about teacher education from the perspective of Inclusive Education. We analyze the contributions of a teacher education program in relation to the teachers' pedagogical practice facing the students with disability. For this purpose, we performed a research in which the study advisors, participants of the Pacto Nacional pela Alfabetização na Idade Certa (PNAIC) (National Pact for Literacy at the Right Age), from the state of Rio Grande do Sul (Brazil), reflected on the possible contributions of this program for their pedagogical practices facing the students with disability. Having said that, 347 study advisors answered to a structured interview, where we found that PNAIC contributed with the inclusive pedagogical practice of $74.06 \%$ of these teachers. Furthermore, to $95.1 \%$ of them, PNAIC contributed with a program of continuing education, qualifying their pedagogical practices. Therefore, we believe that PNAIC collaborated to re-signify the pedagogical practice of many teachers, besides giving the opportunity to an Inclusive Education, despite being still incipient.
\end{abstract}

Keywords: Inclusive Education. Teacher education. National Pact for Literacy at the Right Age.

Resumen: Este artículo tiene como finalidad discutir sobre la formación de docentes bajo la perspectiva de la Educación Inclusiva. En él se analizan las contribuciones de un programa de formación docente en la práctica pedagógica frente a alumnos con discapacidad. Para llevar a cabo la discusión, se realizó una investigación en la que los profesores Orientadores de Estudio, participantes del Pacto Nacional por la Alfabetización en la Edad Apropiada - PNAIC, Rio Grande del Sur, reflexionaron sobre las posibles contribuciones de este programa para sus prácticas pedagógicas frente a los alumnos con discapacidad. Por lo tanto, 347 Orientadores de Estudios respondieron a una entrevista estructurada, en la que se constató que el PNAIC contribuyó con la práctica pedagógica inclusiva de 74,06\% de estos docentes. Además, para 95,1\% de ellos, el PNAIC contribuyó como un programa de formación continua cualificando sus prácticas pedagógicas. Siendo así, se cree que el PNAIC colaboró para reafirmar la práctica pedagógica de muchos docentes, además de crear oportunidades de formación, aunque incipiente, sobre la Educación Inclusiva.

Palabras clave: Educación Inclusiva. Formación Docente. Pacto Nacional por la Alfabetización en la Edad Apropiada.

\title{
Introdução
}

A educação inclusiva é uma realidade presente na maioria das escolas brasileiras. No entanto, o acesso à escola regular não garante a qualidade do ensino recebida pelos alunos público-alvo da educação especial, ou seja, pelos alunos com deficiências, transtornos globais do desenvolvimento e altas habilidades/superdo- 
tação (BRASIL, 2008). Na atual perspectiva da educação inclusiva, almeja-se que $\mathrm{o}$ aluno inserido ingresse na escola comum e que nela permaneça com igualdade de oportunidades, para que assim possa desenvolver-se como os demais alunos que compõem a escola do século XXI.

Tendo em vista que, por muito tempo, os alunos público-alvo da Educação Especial permaneceram à margem social, há ainda privações de acesso a muitos espaços, entre eles o educacional. A partir disso, torna-se necessário discutir sobre os processos de inclusão disseminados nos dias atuais. Essa discussão é fundamental para se refletir a respeito da significação da formação inicial e continuada dos professores que atuam nas escolas que seguem uma perspectiva inclusiva. Para isso, apresentar-se-á uma breve contextualização histórica para se compreender quais foram os caminhos percorridos por estes alunos.

\section{Contextualizando a inclusão escolar}

$\mathrm{Na}$ Antiguidade, cultivava-se o corpo perfeito. Na sociedade grega, em Esparta, por exemplo, os homens tinham dedicação praticamente exclusiva à guerra. A sociedade como um todo enfatizava a beleza física. A força e a beleza tornaram-se um dos grandes objetivos desse povo, tanto que, "se, ao nascer, a criança apresentasse qualquer manifestação que pudesse atentar contra o ideal prevalecente, era eliminada”. (BIANCHETTI, 1998, p. 29). Dessa maneira, as pessoas com deficiência não se enquadravam no perfil desejado, sendo, então, sacrificadas ou abandonadas.

Já para os atenienses, havia uma supervalorização do intelecto. Aos homens livres cabia o ofício de comandar/governar e, por consequência, restava aos escravos executar as demais tarefas. A relação que se estabelecia entre estes povos era de corpo/mente. Portanto, novamente, não havia espaço para a participação social da pessoa com deficiência, uma vez que a mente não poderia contribuir para essa sociedade "pensante".

Já na Idade Média, ou período feudal, a relação exaltada era entre corpo alma. Restava às pessoas deficientes a exclusão, em que "o indivíduo que não se enquadra[va] no padrão considerado normal [...] passa[va] a ser estigmatizado, pois, para o moralismo cristão/católico, a diferença passa a ser um sinônimo do pecado". (ALENCAR; FLEITH, 2001, p. 30). Com base nessa citação, é possível verificar que, nesse período histórico, a Igreja Católica exerceu forte influência na sociedade.

É importante destacar que a Idade Média compreendeu um longo período (entre o século V e o XV). Com isso, a prática de exclusão durou por muitos anos, em que ora as pessoas deficientes eram excluídas, ora, exterminadas Em alguns 
momentos, foram consideradas instrumentos de Deus. Foi por meio da influência do Cristianismo, que as pessoas com deficiência passaram a ser consideradas "filhos de Deus", as quais, portanto, passaram a ser dotadas de uma alma que precisava ser amparada, sob o viés da caridade.

Durante a Inquisição (século XVIII), muitas pessoas foram executadas nas fogueiras, entre elas, as pessoas com deficiência. A justificativa para tal ato era a de que os corpos dessas pessoas estavam possuídos pelo demônio, e que, quando queimados, a Igreja realizava a purificação das almas. Mais adiante, a Igreja Católica considerou as pessoas com deficiência como instrumentos divinos, no sentido de que as pessoas deveriam ser íntegras, respeitosas, não pecadoras para que sua família não fosse "alvo" do nascimento de um deficiente. Além disso, já que os deficientes existiam, cabia aos demais praticar a caridade. "Assim, a desgraça de uns proporcionava meios de salvação a outros". (BIANCHETTI, 1998, p. 33).

A Idade Moderna compreendeu o início do modelo capitalista. Para a sociedade em geral, houve uma mudança significativa no que diz respeito às relações econômicas. Para Bianchetti (1998, p. 34),

O gradativo predomínio de uma produção voltada para o mercado, a possibilidade de acumulação, o desenvolvimento de uma ciência e de tecnologias que garantirão o domínio do homem sobre a natureza diferencia-se radicalmente da situação anterior na qual a maioria dos homens e das mulheres vivia seu dia-a-dia miseravelmente envolvida com a produção para a subsistência.

A partir dessa transformação social, com as descobertas científicas e as navegações, surgiram novas classes sociais; entre as quais a burguesia, como a classe hegemônica responsável por ditar as regras. Nesse contexto, muitos cientistas firmaram suas teorias, como, por exemplo: Copérnico, Galileu Galilei, Bacon, Newton, entre outros. Com essas novas teorias, as máquinas tiveram grande influência para um eficiente funcionamento dos projetos científicos, principalmente a partir da Revolução Industrial (final do século XVIII).

Essa transformação resultou na ideia de que o próprio corpo era como uma "máquina perfeita". "Dessa visão vai emergir um resultado desastroso para a questão da diferença: se o corpo é uma máquina a excepcionalidade ou qualquer diferença, nada mais é do que a disfunção de alguma peça dessa máquina”. (BIANCHETTI, 1998, p. 36). Então, na Idade Moderna, as pessoas com deficiência passaram a ter relação com a disfuncionalidade, ou seja, um corpo que não funciona nos mesmos parâmetros que a indústria necessita. Por fim, a deficiência passou a ser responsabilidade médica e não mais da igreja.

Na Idade Contemporânea, que compreende os séculos XVIII e XIX, observam-se os primeiros movimentos para educar as pessoas com deficiência. Foi 
Esquirol (1818) quem começou a estudar os indivíduos que estavam internados em hospitais, aqueles com "[...] incapacidades acentuadas, estigmas físicos bem demarcados e inadequações pessoais e sociais generalizadas [...]" (UFMS, 2004, s/p). A partir de então, observando as peculiaridades dessas pessoas, em especial, a base orgânica, o déficit intelectual e a incurabilidade, que Esquirol lançou a denominação "idiota". Esse fato não teve uma boa repercussão social, já que

[...] a crença na hereditariedade, na irreversibilidade e a ameaça social que representava a condição na época parecem ter sido responsáveis pela marginalização, reprovação social, confinamento em instituições, esterilizações e outros mecanismos visando o controle social da idiotice. (UFMS, 2004, s/p).

Mais adiante, outros pesquisadores alcançaram diferentes resultados no campo educacional a respeito dessas pessoas. Entre eles, pode-se citar: Itard (1774-1838), Seguin (1812-1880) e Montessori (1870-1952). Seus estudos eram baseados em uma perspectiva sensorial, por meio de treino, com a finalidade de recuperar a parte neurológica deficiente. $\mathrm{O}$ primeiro iniciou um trabalho com o menino Victor, em uma tentativa de inseri-lo na sociedade francesa. Já Seguin foi um dos precursores da teoria de Piaget, utilizando-se de seu método para educar as pessoas com deficiência. Por fim, Montessori aprimorou os métodos dos pesquisadores citados, criando, em Roma, um programa para deficientes mentais. Em seu trabalho, Montessori utilizava encaixes, recortes, objetos coloridos e com texturas. Logo, a partir do exposto, é possível afirmar que, na Idade Contemporânea, predominou o modelo da institucionalização/segregação. (BIANCHETTI, 1998).

A partir do século XX, surgiram diferentes modelos educacionais, bem como diferentes terminologias para nomear as pessoas com deficiência. Na década de 1920, os deficientes eram tratados como "pessoas inválidas", sem valor; considerados, assim, inúteis para a sociedade e um "peso" para a família.

Deste período até aproximadamente 1960, o termo utilizado era "incapacitados", mais tarde evoluindo para "indivíduos com capacidade residual”. Isso indica que a sociedade percebeu que essas pessoas poderiam ter algum tipo de capacidade, por exemplo, cognitiva, social ou emocional. Já próximo à década 1970 as instituições especializadas atingiram seu auge: "[...] escolas especiais, centros de reabilitação, oficinas protegidas de trabalho, clubes sociais especiais, associações desportivas especiais" (SASSAKI, 1997, p. 31). Tudo isso por que foram lançados os primeiros movimentos mundiais, em favor das pessoas "incapacitadas".

O primeiro deles foi em 1948, na Declaração Universal dos Direitos Humanos. No documento, no Artigo $1^{\circ}$, foi previsto que "todos os seres humanos nascem livres e iguais, em dignidade e direitos [...]". No Artigo 26, foi apresentado que "toda a pessoa tem direito à educação" (BRASIL, 2004, p. 14). A partir da desta declaração, as pessoas com deficiência passam a ter o direito a frequentar o 
Ensino Fundamental, assim como ter oportunidades para participar do convívio social em comunidade. Dessa forma, foi no final dessa década que iniciaram os movimentos em prol da integração social.

Nessa abordagem de mobilização social, as décadas de 1970 e 1980 foram marcadas pelas movimentações com a finalidade de inclusão social ligada, em especial, à deficiência, surgindo, então, a normalização como princípio norteador da proposta de integração social. Na concepção de Sassaki (1997, p. 32), normalizar "[...] significa criar, para pessoas atendidas ou segregadas de algum modo, ambientes o mais parecido possível com aqueles vivenciados pela população geral”. Logo, com a normalização, houve um movimento para tentar normalizar diversos ambientes, por exemplo, escola, lazer, trabalho, com intuito de oportunizar à pessoa com deficiência vivências com um estilo de vida comum à sociedade/cultura vigente.

Uma das críticas apontadas ao movimento da integração escolar diz respeito ao pouco interesse da sociedade em pôr em prática ações que recebessem as pessoas com deficiência, as quais, todavia, tiveram que se adaptar para conviver no meio social. Isto é, " [...] a sociedade, praticamente de braços cruzados, aceita receber portadores de deficiência desde que estes sejam capazes de: [...] lidar com as atitudes discriminatórias da sociedade, resultantes de estereótipos, preconceitos e estigmas [...]". (SASSAKI, 1997, p. 35). Portanto, nesse movimento de integração, era o deficiente que deveria se adequar à sociedade e não esta que deveria se preparar para recebê-lo.

A partir da década de 1990 até os dias atuais, a inclusão escolar das pessoas com deficiência tem sido foco de grandes debates. A Conferência Mundial sobre Educação para Todos, realizada em Jomtien, na Tailândia, em 1990, foi um dos primeiros marcos relacionados às políticas públicas pensadas para garantir a inclusão. Assim como outros países, o Brasil também participou dessa conferência e assinou o acordo estabelecido entre os participantes que assumiram, entre outros, o seguinte compromisso:

Artigo $3^{\circ}$, item 5 - As necessidades básicas de aprendizagem das pessoas portadoras de deficiências requerem atenção especial. É preciso tomar medidas que garantam a igualdade de acesso à educação aos portadores de todo e qualquer tipo de deficiência, como parte integrante do sistema educativo. (UNESCO, 1990).

Diante disso, observa-se que, no início da referida década, já estavam bem delineados alguns propósitos referentes à inclusão escolar, entre os quais, "a igualdade de acesso à educação" como princípio pertinente e desejado até os dias atuais, mesmo com o passar de 25 anos dessa conferência.

Outro importante marco mundial para a inclusão escolar aconteceu em Salamanca, na Espanha, no ano de 1994, momento no qual vários líderes e gover- 
nantes se comprometeram em implantar a inclusão escolar em seus respectivos países, inclusive no Brasil. Dentre os princípios aprovados na Declaração de Salamanca, encontra-se que o

Princípio fundamental da escola inclusiva é o de que todas as crianças devem aprender juntas, sempre que possível, independentemente de quaisquer dificuldades ou diferenças que elas possam ter. Escolas inclusivas devem reconhecer e responder às necessidades diversas de seus alunos, acomodando ambos os estilos e ritmos de aprendizagem e assegurando uma educação de qualidade a todos através de um currículo apropriado, arranjos organizacionais, estratégias de ensino, uso de recurso e parceria com as comunidades. $\mathrm{Na}$ verdade, deveria existir uma continuidade de serviços e apoio proporcional ao contínuo de necessidades especiais encontradas dentro da escola. (UNESCO, 1994, p. 5).

Dessa forma, pelo viés da educação inclusiva, não é mais a pessoa com deficiência que precisa se adequar aos espaços, como acontecia na integração. Agora, são os espaços que devem ser organizados para receber a pessoa com deficiência. É a sociedade que precisa oferecer igualdade de oportunidades a todas as pessoas, inclusive, os indivíduos com deficiência.

Nesse sentido, segundo Mantoan (2008a, p. 37), “a inclusão implica uma mudança de paradigma educacional, que gera uma reorganização das práticas escolares: planejamentos, formação de turmas, currículo, avaliação, gestão do processo educativo". Em conformidade com a autora, espera-se que a escola regular realmente implemente as políticas públicas que respaldam a inclusão escolar. Tendo em vista que elas foram criadas com o intuito de assegurar o ingresso dos alunos com deficiência na escola regular, acredita-se que, posteriormente, eles possam ir além, ou seja, possam assegurar também a permanência desses alunos nesses espaços.

Após brevemente contextualizado o processo linear da história que marcou a inclusão social, serão abordadas as influências desses movimentos internacionais nas políticas públicas educacionais do Brasil.

É importante ressaltar que, desde a Constituição Federal (BRASIL, 1988), podem ser observados alguns movimentos que discutem sobre o direito das pessoas com deficiência. Consta, nesse documento, que todas as pessoas são iguais e devem ser respeitadas em suas particularidades e necessidades específicas perante a lei. Diante disso, as pessoas com deficiência também estão respaldadas pela Constituição Federal.

No entanto, em 1996 a partir da reformulação da Lei no 9.394, de 1996, Lei de Diretrizes e Bases da Educação Nacional (LDB), verifica-se um avanço expressivo na educação das pessoas com deficiência. Nessa LDB, criou-se um 
capítulo específico sobre a Educação Especial, capítulo V, que especificou sobre a mesma e apresentou algumas discussões em torno da inclusão escolar da pessoa com deficiência e outras necessidades educacionais especiais, que, naquela época, compunham os alunos-alvo da Educação Especial.

O artigo 58 define que a Educação Especial é:

Uma modalidade de educação escolar, oferecida preferencialmente, na rede regular de ensino, para educandos portadores de necessidades especiais.

$\int 1^{\circ}$ Haverá, quando necessário, serviços de apoio especializado, na escola regular, para atender às peculiaridades da clientela de educação especial.

$\S 2^{\circ} \mathrm{O}$ atendimento educacional será feito em classes ou serviços especializados, sempre que, em função das condições específicas dos alunos, quando não for possível a sua integração nas classes comuns de ensino. (BRASIL, 1996).

Já o Artigo 59, destaca que:

Os sistemas de ensino assegurarão aos educandos com necessidades especiais: I - currículo, métodos, técnicas, recursos educativos e organização específicos, para atender às suas necessidades;

II - terminalidade específica para aqueles que não puderem atingir o nível exigido para a conclusão do ensino fundamental, em virtude de suas deficiências, e aceleração para concluir em menor tempo o programa escolar para os superdotados;

III - professores com especialização adequada em nível médio ou superior, para atendimento especializado, bem como professores do ensino regular capacitados para a integração desses educandos nas classes comuns;

IV - educação especial para o trabalho, visando a sua efetiva integração na vida em sociedade, inclusive condições adequadas para os que não revelarem capacidade de inserção no trabalho competitivo, mediante articulação com os órgãos oficiais afins, bem como para aqueles que apresentam uma habilidade superior nas áreas artística, intelectual ou psicomotora. (BRASIL, 1996).

A partir do exposto, é possível verificar que esta LDB buscou adequar seu discurso aos ideais da Conferência sobre Educação para Todos e da Declaração de Salamanca, reafirmando o compromisso do Brasil com essas duas políticas públicas internacionais.

Apoiando essa ideia e fazendo um recorte sobre a legislação brasileira, o Ministério da Educação e a Secretaria de Educação Especial publicaram, em 2001, as Diretrizes Nacionais para a Educação Especial na Educação Básica. Nesse documento, a inclusão escolar é definida como “[...] uma nova postura da escola comum, que propõe no projeto pedagógico - no currículo, na metodologia de ensino, na avaliação e na atitude dos educadores - ações que favoreçam a intera- 
ção social e sua opção por práticas heterogêneas”. (BRASIL, 2001, p. 40). Logo, a escola regular deverá organizar-se pedagogicamente para incluir os alunos com deficiência, respaldando suas ações no projeto pedagógico.

Outro aspecto importante nas Diretrizes é a preocupação com a permanência dos alunos com deficiência na escola regular. Segundo o documento, é preciso que o professor do ensino regular adapte suas metodologias de ensino e de avaliação para que o aluno com deficiência tenha igualdade de oportunidades, ou seja, para que sejam oferecidos aos alunos as mesmas oportunidades de aprender, independentemente de estes terem ou não alguma deficiência.

Por fim, foi estabelecida, em 2008, a Política Nacional de Educação Especial na Perspectiva da Educação Inclusiva, que tem como objetivos,

[...] assegurar a inclusão escolar de alunos com deficiência, transtornos globais do desenvolvimento e altas habilidades/superdotação, orientando os sistemas de ensino para garantir: acesso ao ensino regular, com participação, aprendizagem e continuidade nos níveis mais elevados do ensino; transversalidade da modalidade de educação especial desde a educação infantil até a educação superior; oferta do atendimento educacional especializado; formação de professores para o atendimento educacional especializado e demais profissionais da educação para a inclusão; participação da família e da comunidade; acessibilidade arquitetônica, nos transportes, nos mobiliários, nas comunicações e informação; e articulação intersetorial na implementação das políticas públicas. (BRASIL, 2008, p. 14).

Além disso, a Política trouxe a necessidade de articular o trabalho do pedagogo com o do professor especialista, já que a inclusão escolar precisa ser responsabilidade de toda a comunidade escolar. Nesse contexto, o professor especialista realiza o Atendimento Educacional Especializado (AEE), que:

[...] identifica, elabora e organiza recursos pedagógicos e de acessibilidade que eliminem as barreiras para a plena participação dos alunos, considerando as suas necessidades específicas. As atividades desenvolvidas no atendimento educacional especializado diferenciam-se daquelas realizadas na sala de aula comum, não sendo substitutivas à escolarização. Esse atendimento complementa e/ou suplementa a formação dos alunos com vistas à autonomia e independência na escola e fora dela. (BRASIL, 2008, p. 16).

Para tanto, o professor do AEE avalia pedagogicamente o aluno público-alvo da educação especial para, a partir disso, estabelecer um plano individual de ação pedagógica. Esse plano deverá ser discutido com o professor do ensino regular, tendo em vista que este deverá dar continuidade a esse plano na sua sala de aula, articulando os objetivos de aprendizagem desse aluno com os objetivos estabelecidos para os demais alunos. Em outras palavras, o plano de ensino do 
aluno incluído deverá ser organizado dentro de uma proposta que também estará sendo desenvolvida com os demais colegas de sua turma. Essa não é uma tarefa simples, exige um compromisso a mais por parte do professor, pois, além de ele planejar suas aulas aos demais seus alunos, ele deverá adequá-las às necessidades apresentadas pelo aluno incluído. Isso significa incluir, isto é, oportunizar que todos participem, que tenham igualdade de oportunidades. Mas como garantir essa igualdade sem adaptações?

Diante disso, como referido anteriormente, a inclusão é responsabilidade de todos; por isso, a escola regular precisa construir seu projeto pedagógico atentando para essas questões, assegurando que o aluno com deficiência tenha acesso a um currículo flexível, a materiais adaptados, tecnologia assistiva, a avaliações diferenciadas, ou seja, acesso a adaptações que oportunizem a esse aluno ter igualdade de oportunidades para, assim, ter a oportunidade de construir seu conhecimento e progredir na vida escolar. Não obstante, caso a escola não organize sua proposta por esse viés, além de não garantir a inclusão do aluno, ela estará excluindo-o desse processo e privando-o da igualdade de oportunidades, ou seja, privando-o de seu desenvolvimento como cidadão.

Com base no exposto, pode-se afirmar que, para que a inclusão seja efetivada, é imprescindível que se estabeleçam parcerias: que o professor especialista e professor do ensino comum trabalhem em conjunto, que a equipe diretiva seja apoiadora desse processo e que a família seja o suporte necessário ao longo desse percurso.

A breve descrição sobre a Educação Especial (sob o viés inclusivo) que foi apresentada até aqui teve a intenção de contextualizar e mostrar o processo o qual as pessoas com deficiência percorrem até terem o direito de tornarem-se alunos de uma escola regular. Entretanto, com a finalidade de atender e receber todos os alunos, alguns os professores não receberam nem recebem uma formação de qualidade. A respeito disso, passar-se-á a discutir sobre a importância da formação inicial e continuada do professor para atuar na perspectiva da educação inclusiva.

\section{Formação de professores para atuar na perspectiva da educação inclusiva}

A inclusão dos alunos com deficiência desacomoda tanto professores quanto gestores, pois ela exige de cada segmento práticas diferenciadas e conhecimentos sobre uma temática a que muitos professores não tiveram acesso ao longo de sua formação inicial. Essas exigências têm movimentado o cenário educacional, criando possibilidades de formação para que esses professores tenham capacidade de atender o público da Educação Especial. 
Não é raro observar o despreparo que muitos professores sentem no recebimento desses alunos. Portanto, essa temática tem sido incluída nos cursos de formação continuada de professores. No ano de 2012, o Ministério da Educação (MEC), juntamente com a Secretaria de Educação Básica (SEB), desenvolveu o programa Pacto Nacional pela Alfabetização na Idade Certa (PNAIC) ${ }^{1}$. O referido programa é uma política pública que busca assegurar que todas as crianças sejam alfabetizadas até os oito anos de idade. Suas ações compreendem: formação continuada para os professores do Ciclo de Alfabetização, distribuição de materiais didáticos às escolas públicas, avaliações quanto à aprendizagem dos alunos e à gestão, mobilização e controle social². Sua programação inclui orientações a respeito de: Currículo, Currículo inclusivo, Planejamento escolar, reflexões sobre o Sistema de Escrita Alfabética, Ludicidade, Diversidade/Heterogeneidade, Educação do campo e Educação especial, que são temas de debates muito sensíveis dentro das escolas e importantes quando se almeja uma educação de boa qualidade.

O professor, muitas vezes, é considerado elemento central para a melhoria da educação brasileira. Dessa forma, nas últimas décadas, tem-se percebido que sua formação está no centro das discussões com o objetivo de transcender os principais problemas encontrados nas escolas do país. Conforme Imbernón (2010), é no início dos anos 1990, com a aceleração da era tecnológica e a evolução da sociedade, que a formação continuada tomou força. Então, começou-se a compreender que o professor deveria atualizar suas metodologias de ensino, pois seus alunos estavam mudando de perfil. Nesse período, eles tinham o conhecimento da era digital.

Época de grandes mudanças, na qual começamos a ser conscientes da evolução acelerada da sociedade em suas estruturas materiais, institucionais e formas de organização da convivência, bem como em seus modelos de produção e distribuição. (IMBERNÓN, 2010, p. 22).

Nesse sentido, a formação continuada foi uma saída encontrada para que os professores pudessem, com um olhar crítico e reflexivo sobre suas práticas, (re)significá-las. Imbernón (2010, p. 96) contribui para essa afirmação ao pontuar que "a formação continuada deve levar em conta que, mais do que atualizar o professor e ensiná-lo, cria as condições, elabora e propicia ambientes para que os docentes aprendam", devendo ser um espaço de reflexões significativas àqueles que nele estão.

\footnotetext{
1 "Este Programa do Ministério da Educação se desenvolve em parceria com universidades públicas brasileiras e secretarias de educação. Não há como garantir a efetividade da formação docente sem a participação ativa desses três segmentos. Cada um desses tem funções específicas a fim de garantir o bom andamento do programa” (BRASIL, 2012, p. 27).

${ }^{2}$ Disponível em: <http://pacto.mec.gov.br/component/content/article/2-uncategorised/53-entendento-opacto>. Acesso em: 25 maio 2014.
} 
A figura do professor está diretamente ligada à aprendizagem do aluno, ao desenvolvimento da escola e aos índices escolares. Isso resulta na oferta de muitos cursos que abordem sua profissão, as melhores formas de ensinar, o comportamento infantil, enfim, questões relacionadas à sua prática e àquilo que é considerado relevante para um trabalho comprometido e que gere resultados positivos. Lima (2003, p. 28) afirma que "[...] há indícios de que maior capacitação docente pode levar a melhores resultados de aprendizagem", atribuindo ao professor às melhorias dos aspectos citados anteriormente.

Ser sujeito da formação implica participar ativamente das oportunidades que surgem para o aprimoramento de suas práticas e, também, refletir sobre o valor dessa formação para a sua profissão de professor.

Na medida em que a orientação inclusiva implica um ensino adaptado às diferenças e às necessidades individuais, os educadores precisam estar habilitados para atuar de forma competente junto aos alunos inseridos nos vários níveis de ensino. [...] O que se tem colocado em discussão, principalmente, é a ausência de formação dos educadores para trabalhar com essa clientela, e isso certamente se constitui em um sério problema na implantação de políticas desse tipo. (NASCIMENTO, 2009, p. 5).

É preciso que o professor acredite nos potenciais presentes nos alunos com deficiência, evitando a acomodação perante situações que necessitam ser modificadas, por meio, por exemplo, da adaptação de avaliações e métodos de ensino, para que sejam condizentes com a aprendizagem desses alunos.

Diante disso, é importante que o professor se envolva nos cursos de formação continuada, que lhe oportunizam possibilidades que vão ao encontro das necessidades encontradas na sua realidade frente à situação da inclusão. Conforme Nascimento (2009, p. 6), "o professor, na educação inclusiva, precisa ser preparado para lidar com as diferenças, com a singularidade e a diversidade de todas as crianças e não com um modelo de pensamento comum a todas elas". No entanto, infelizmente, essas práticas ainda são muito comuns nas escolas que se dizem inclusivas. É preciso acreditar que a inclusão é uma política séria, que envolve não só o acesso à escola, mas também as condições de permanência nela do aluno com deficiência.

[...] é necessário garantir o acesso à escola, mas isso não basta. É necessário garantir as condições de aprendizagem para que todos os alunos, mas isso também não basta! É necessário discutir como se situa a escola na sociedade e como esta sociedade produz seus excluídos, bem como reage a eles em várias instâncias, uma delas sendo a formação de professores que, na escola, dizem-se incapazes de lidar com alunos diferentes daqueles com os quais estão habituados. (BRASIL, 2014, p. 8). 
Nesse sentido, a inclusão escolar, necessita ser discutida, cada vez mais, nos cursos de formação continuada de professores pedagogos, a exemplo do PNAIC, para que a política da educação inclusiva seja, de fato, efetivada. Isso se faz relevante porque se considera que o professor, não unicamente, mas especialmente, assume um papel importante para que a educação seja um direito de todos, em um espaço comum a todos os seres humanos.

Há a concepção de que professor assume papel importante/central no espaço escolar e, portanto, ele é um dos agentes principais para garantir a permanência dos alunos com deficiência na escola comum. No entanto, é preciso que esses professores estejam preparados e abertos para receber esse público, já que, com a chegada desses alunos, serão exigidas adaptações em todos os segmentos da escola.

Carvalho (2006a, p. 72) comenta sobre as barreiras que devem ser superadas para que a inclusão escolar seja efetivada. Para a autora,

O que se pretende na educação inclusiva é remover barreiras, sejam elas extrínsecas ou intrínsecas aos alunos, buscando-se todas as formas de acessibilidade e de apoio de modo a assegurar (o que a lei faz) e, principalmente garantir (o que deve constar dos projetos político-pedagógicos dos sistemas de ensino e das escolas e que deve ser executado), tomando-se as providências para efetivar ações para o acesso, ingresso e permanência bem sucedida na escola.

Assim, "tanto as barreiras físicas quanto as atitudinais precisam ser removidas para que a inclusão escolar seja uma realidade. Certamente, as barreiras atitudinais serão as mais difíceis e demoradas de serem removidas". (FREITAS; RECH, 2015. p. 6).

Prosseguindo com a discussão a respeito da formação de professores, observa-se que há uma recorrência, nos discursos dos professores, de que a formação inicial recebida por eles foi incipiente quanto à realidade da inclusão dos alunos com deficiência. Nesse sentido, os cursos de formação continuada, os quais têm como um de seus objetivos o estudo sobre a Educação Especial e Inclusão, tornam-se importantes para a melhoria da aprendizagem desses alunos. Tendo em vista que esses sujeitos estruturam o conhecimento de maneiras diferenciadas, requerem do professor uma atitude distinta daquela assumida frente aos demais alunos, que não apresentam deficiências. Assim, é preciso buscar um fazer pedagógico que acredite na aprendizagem desses alunos, compreendendo-os como sujeitos capazes de aprender dentro de seus tempos e estilos de aprendizagem.

Para tanto, os professores precisam estar preparados para recebê-los, abertos a novas metodologias de trabalho, a novas maneiras de enxergar o ser humano e de acreditar que todos são capazes de aprender, independentemente da deficiência e das diferenças apresentadas. Além disso, conforme aponta Freire (1996, p. 43), "na 
formação permanente dos professores, o momento fundamental é o da reflexão crítica sobre a prática". A partir disso, são percebidas as potencialidades e as possibilidades que o PNAIC tem propiciado à formação continuada dos professores.

A formação continuada de professores comprometida eticamente com os preceitos do exercício da profissão de professor é capaz de permitir que o passar dos anos não diminua a esperança na capacidade do outro de ensinar e aprender e na sua vontade progressiva de conhecer. Freire (1996, p. 27) afirma que "quanto mais criticamente se exerce a capacidade de aprender, tanto mais se constrói e desenvolve" o que ele chama de "curiosidade epistemológica, sem a qual não alcançamos o conhecimento cabal do objeto".

Diante da contextualização e do aporte teórico apresentado ao longo desta seção, serão expostos, na próxima, os resultados encontrados na pesquisa realizada com professores que participaram do PNAIC, com o objetivo de detectar as principais contribuições que o programa teve em suas práticas pedagógicas frente aos alunos com deficiência, bem como a contribuição do programa como curso de formação continuada de professores.

\section{Influências do PNAIC na formação docente}

Inicialmente foram analisadas as respostas à primeira questão, que buscou esclarecer: "De que forma o PNAIC colaborou para sua formação profissional?". Pergunta à qual 330 Orientadores de Estudo afirmaram que o Programa contribuiu para sua formação profissional, 13 disseram que contribuiu parcialmente, dois, que não houve contribuição, e dois não souberam opinar, conforme evidencia o Gráfico 1.

Gráfico 1 - Referente à colaboração do PNAIC como programa de formação continuada de professores

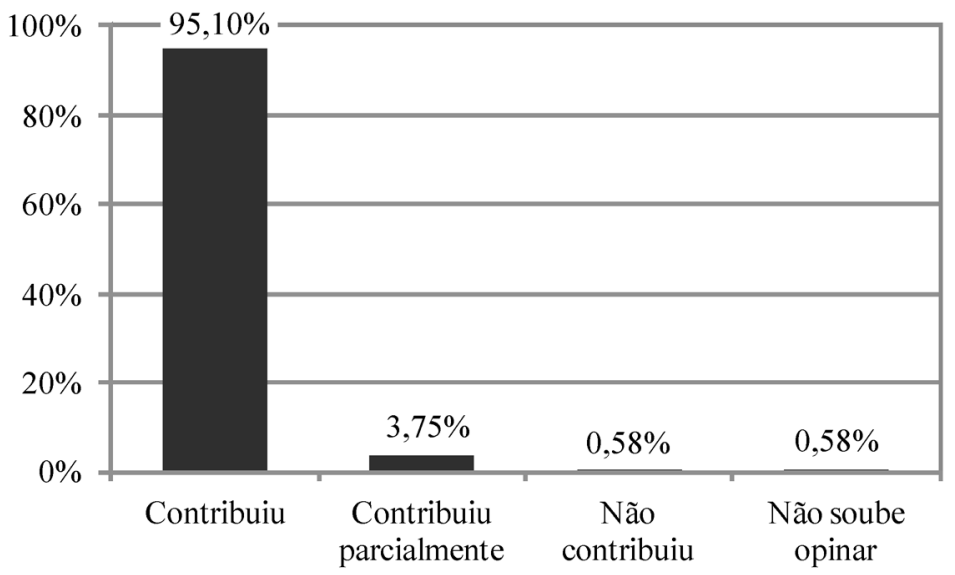

Fonte: Elaborado pelas autoras (2015). 
O PNAIC foi um curso de formação continuada de professores que contribuiu significativamente para a formação profissional de cada um. Por meio dos fragmentos retirados da entrevista estruturada, identificaram-se, na opinião de vários entrevistados, referências à troca de experiências, ao compartilhamento de seus saberes e preocupações e à socialização de ideias entre os participantes, como fatores importantes para a sua formação.

Solidificou e abriu novos horizontes. Socializando experiências e juntos achando alternativas para nossas práticas do dia-a-dia no cotidiano escolar. (Relato da Professora "12").

Integração de conhecimentos e troca com outros municípios; desacomodação do professor (materiais); busca do aprender a aprender; compartilhar saberes e preocupacões. (Relato da Professora "62").

Com a socialização nos grupos a construção do conbecimento se amplia gerando novos conflitos e busca de alternativas para resolver as dificuldades de aprendizagem visando uma educação de qualidade. (Relato da Professora "49").

Percebe-se que o grupo se caracterizou como um dispositivo de formação, pelas trocas que seus participantes fizeram ao estarem imbricados nele, pois, desde que se entra na escola, aprende-se pela convivência com os pares, experimentando o que está em volta, criando significações sobre o que está no mundo. O papel do outro na vida é de extrema importância para a construção pessoal, já que é por meio das relações humanas que nos construímos diariamente.

A construção profissional também acontece com os pares, compartilhando os saberes, construindo olhares mais atentos ao seu próximo e valorizando os diferentes saberes. Nessa perspectiva, o grupo configurou-se como dispositivo de formação, pois, através da convivência com o outro, tornaram-se mais sensíveis ao que acontece com o próximo e também porque as pessoas que compõem esse grupo trazem consigo suas vivências, suas significações e suas reflexões sobre as experiências que vão contribuindo para o coletivo. Desse modo, acredita-se que os diferentes modos de pensar geram aprendizagens significativas, que são de suma importância, já que o professor necessita valorizar os diferentes saberes e os diferentes tipos de aprendizagens que encontrarão em seus alunos no seu espaço de trabalho.

O grupo, como dispositivo de formação, permite que seus integrantes compartilhem suas experiências e suas percepções a respeito da profissão e exercitem o escutar ao outro. Oliveira (2010, p. 3) contribui colocando que

O dispositivo passa a ser entendido como qualquer lugar/espaço no qual se constitui ou se transforma a experiência de si, um movimento em que o sujeito está implicado. Implica consigo, implicando-se a partir dos outros e implicando com os outros. O diferencial que encontramos no acréscimo da 
questão do dispositivo está na inscrição da pessoa no lugar formativo como alguém que se coloca, se experimenta, não participa passivamente, ouvindo teorizações sobre experiências produzidas por outros, mas (re)visita seus repertórios formativos, problematizando-os também na escuta do outro.

Logo, cabe ressaltar que, o estar imbricado ao grupo é que o caracterizará como dispositivo de formação. Não basta estar nele, passar por ele; é necessário que ele seja, de fato, importante, que permita ressignificações, reflexões ou até mesmo mudanças de comportamentos. Esses detalhes foram notados em muitos dos relatos realizados pelos professores Orientadores de Estudos.

Outra questão importante, mencionada em alguns dos fragmentos das entrevistas, é a responsabilidade que o professor toma para si pela melhoria da educação. Logo, o PNAIC veio para contribuir para uma educação de melhor qualidade, evidenciando o professor como agente transformador dessa melhora na qualidade do ensino.

Proporcionando um aprendizado enriquecedor, construtivo, inovador com novas técnicas para ampliação das experiências humanas na aproximação, compreensão, valorização na construção do conhecimento contextualizado e humanizador. E que a nossa missão de ensinar a cada dia torna-se mais gratificante e que nós podemos fazer a diferença. (Relato da Professora “258”).

Proporcionou momentos de construção de conhecimento e oportunidade de repensar/reavaliar a nossa prática pedagógica para melhorar a qualidade da educaşão do município e do país. (Relato da Professora “'32”).

Com os estudos dos cadernos do PNAIC e pelas experiências vivenciadas pelos professores alfabetizadores e socializadas para todo o grupo, pudemos perceber que a educação de qualidade pode ser uma realidade em nosso município, e não apenas ser uma utopia. (Relato da Professora "6").

Com base nos relatos, percebe-se que os professores acreditam que a sua formação continuada é uma possibilidade para que a educação brasileira contemple a necessidade de todos os alunos presente nas escolas e que auxilie na melhoria dos índices de aprendizagem do nosso país. Lima (2003, p. 25, grifo da autora) contribui afirmando que

[...] sobre os professores repousam os anseios e as responsabilidades pelo desenvolvimento de todo o processo educativo. A eles é atribuída uma hiper-responsabilidade pela prática pedagógica e pela qualidade do ensino. A eles, em especial, é atribuída a tarefa de melhorar a aprendizagem.

Vê-se, assim, que o professor é um ator de suma importância na cena educacional; todavia, não se pode responsabilizá-lo pelos fracassos que, muitas vezes, são vivenciados em nossas escolas. Os alunos são seres multifacetados e devem ser de responsabilidade de todos, tanto no espaço educacional quanto no social. 
De acordo com diversas falas dos professores participantes da pesquisa, o PNAIC permitiu uma avaliação contínua e uma reflexão de suas práticas, por meio do estudo dos cadernos e do contato com outros professores, de modo a construir saberes no grande grupo.

Contribuiu ao propor a autoavaliação constante, para um planejamento com intervenções pedagógicas que contemplem, não apenas a leitura e a escrita, como também insiram a ludicidade e as diferentes formas de organização das salas em seu planejamento. (Relato da Professora “50”).

O pacto foi maravilhoso na minha formação profissional através das leituras, dinâmicas, momentos de reflexão, trocas de experiências. Passei a perceber a necessidade de buscarmos constantemente avaliar a nossa prática com o objetivo de realizarmos um trabalho de qualidade. (Relato da Professora 39).

Auxiliou na medida em que podemos nos avaliar, refletir sobre nossas práticas. E a necessidade de pesquisa/ação/leituras. (Relato da Professora 33).

Muitos estudiosos da área de formação continuada de professores expõem que a reflexão sobre a prática é uma das principais contribuições de uma formação contínua. Formação essa que permite ao professor não se acomodar às práticas defasadas, que já não funcionam mais com alunos que estão chegando nas escolas atualmente. Neubauer et al. (2005, p. 61) corroboram com essa ideia quando colocam que "o aprender contínuo é essencial" e que através do "processo de reflexão sobre a prática, o professor poderá reavaliar a sua ação metodológica, bem como o conjunto de valores e princípios que sustentam o trabalho pedagógico".

Além disso, a experiência no PNAIC foi uma oportunidade de retomar teorias estudadas ao longo do curso formador dos professores, as quais puderam ser melhores compreendidas a partir do percurso de experiências que todos percorreram, como pode ser percebido nos seguintes fragmentos:

Para mim foi uma oportunidade de fazer uma retomada profissional e me desafiar a buscar teoria e praticamente alternativas de formação para envolver as professoras alfabetizadoras. (Relato da Professora “41”).

Aprofundando conbecimentos já existentes. Contribuindo com novos conhecimentos. Estimulando práticas de estudo, busca e atuação com entusiasmo. (Relato da Professora "20").

A formação continuada, de fato, contribui para a oportunidade de retomar e aprofundar questões que já tinham sido estudadas na formação inicial. Arrisca-se afirmar que essa retomada oportuniza a esses professores um saber debruçado em suas práticas e, portanto, mais significativo e melhor compreendido por eles, pois, como bem mencionam Neubauer et al. (2005, p. 66), "os saberes experienciais influenciem significativamente a prática educativa". 
Além disso, ressalta-se que essa formação ultrapassou a formação profissional, influenciando também na vida pessoal de cada professor. O PNAIC foi, na vida desses professores, também um fator de motivação, de engajamento, de mudança de concepções acerca da heterogeneidade que existe em uma turma e de valorização dos pequenos avanços daqueles alunos que têm mais dificuldade. $\mathrm{O}$ Programa motivou a busca pelo novo, pelo diferente, e negou práticas que excluem aqueles que apresentam maiores dificuldade para aprender. Aspectos como esses foram mencionados pelos professores participantes da pesquisa.

Passei a perceber que as coisas simples podem significar muito e cada trabalho é necessário ser registrado para que possa ser lembrado. É preciso muita reflexão para com nossa prática. (Relato da Professora "42").

Colaborou de maneira significativa, me motivando a buscar cada vez, mais. Abrindo caminhos para que eu também pudesse ajudar, não só os educandos, mas também as professoras alfabetizadoras. Colaborou nos dando suporte teórico para nossas práticas. (Relato da Professora "123").

O pacto veio para nós fazermos uma análise da nossa prática e também para dar uma revigorada no nosso trabalho, como também novas ideias de como melhorar nossa aprendizagem tendo também um olhar diferente perante nossos alunos. (Relato da Professora "266”).

Sendo assim, por meio desta pesquisa, percebeu-se que o PNAIC veio a contribuir em muitos aspectos para os professores Orientadores de Estudos. A estrutura organizacional que caracteriza o PNAIC colocou o professor em um lugar que não apenas irá sofrer influências de uma formação, mas em que também agirá e refletirá sobre ela.

\section{Participação no PNAIC e prática pedagógica inclusiva: algumas considerações}

A segunda questão que os Orientadores de Estudo responderam foi: "De que forma o PNAIC contribuiu para sua prática pedagógica frente aos alunos com deficiência? Se não contribuiu, destaque os principais motivos".

Após analisar as respostas, concluiu-se que, para 257 Orientadores de Estudo, o PNAIC contribuiu para sua prática pedagógica frente aos alunos com deficiência; para 48 deles, contribuiu parcialmente; para 21 deles, não contribuiu e 21 não souberam responder. Essa distribuição está ilustrada no Gráfico 2. 
Gráfico 2 - Elaborado a partir das respostas dos Orientadores de Estudo sobre as contribuições do PNAIC para sua prática pedagógica frente os alunos deficiência

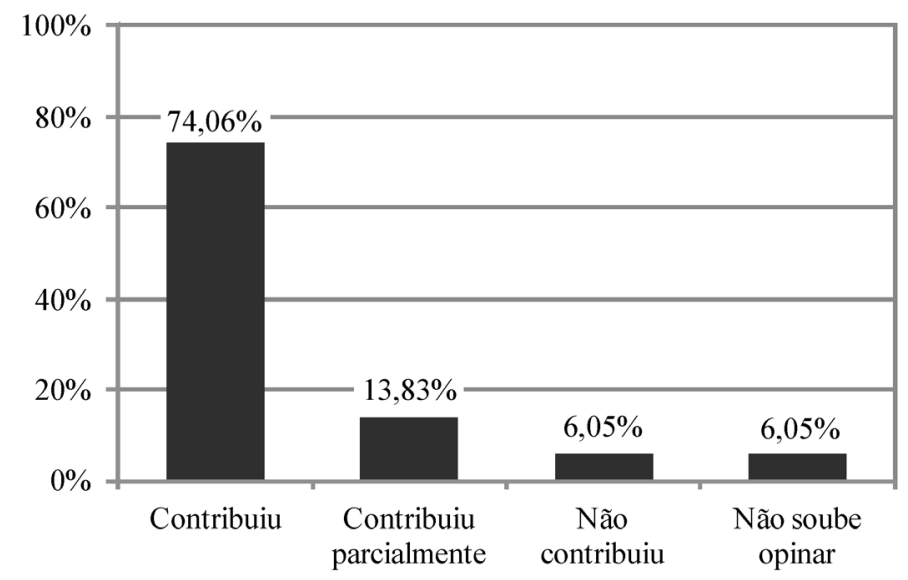

Fonte: Elaborado pelas autoras (2015).

Após verificar as respostas dos participantes, observou-se que os professores perceberam que devem respeitar/compreender os diferentes ritmos de aprendizagem dos alunos com deficiências, pois, assim, estes terão iguais oportunidades para aprender, como seus colegas que não têm deficiência.

Tenho dois alunos incluídos e as formações do PACTO muito contribuíram para o meu trabalho de ensino e aprendizagem dos mesmos. Passei a compreendê-los de forma diferenciada, respeitando suas limitações, criando estratégias e novas formas de melhor contemplá-los com a aprendizagem [...]. (Relato da Professora "43").

Contribuiu para melhorar o entendimento de que cada ser humano aprende cada um a seu tempo e modo. (Relato da Professora "106").

Beyer (2013, p. 28) faz uma importante reflexão quando afirma que "precisamos entender que as crianças são diferentes entre si. Elas são únicas em sua forma de pensar e aprender. Todas as crianças, não apenas as que apresentam alguma limitação ou deficiência [...]”. Pelos relatos selecionados para ilustrar essas discussões, observou-se que os professores estão atentos para essas situações, ou seja, para o dever de respeitar a individualidade de cada aluno e, como consequência, compreender que cada aluno apresentará diferentes ritmos ao aprender, independentemente de ter ou não deficiência. A Professora "50" comenta sobre isso. Para ela: "A formação contribuiu quando destacou que todas as crianças devem ser observadas e contempladas na sua singularidade, sejam elas deficientes ou não".

Outra contribuição que os participantes do PNAIC trouxeram à reflexão foi a de que eles passaram a compreender que devem organizar seu trabalho a 
partir dos potenciais que os alunos com deficiência apresentam, e não a partir de suas limitações.

Contribuiu no sentido de mostrar que cada ser/sujeito é único e que precisa ser respeitado dentro de sua individualidade e que precisamos apostar nas suas potencialidades e não nas falhas. (Relato da Professora “217”).

Contribuiu para que pudéssemos olhar e pensar esse aluno com um entendimento diferente, percebendo suas potencialidades e criando ambientes adequados a sua aprendizagem [...]. (Relato da Professora “227”).

Contribuiu para tirar os alunos do fundo da sala e uni-los aos demais. Entendi que todos são capaz̧es de aprender. (Relato da Professora "286").

Os relatos comprovam que as professoras reconhecem que o trabalho com os alunos com deficiência precisa ir além da socialização. Nesse contexto, o professor precisa acreditar e visualizar os potenciais que os alunos com deficiência apresentam, como afirma a Professora "39": "Passei a observar mais esses alunos, reconhecendo a importância de se integrar os mesmos com os demais, respeitando as diferenças identificando as possibilidades de cada aluno".

A crença de que o aluno com deficiência tem potencial para aprender foi conquistada após muita discussão e muitos anos de pesquisas. Tudo isso, pois, por muito tempo, principalmente o aluno com deficiência cognitiva ficou limitado ao estímulo do seu desenvolvimento motor e psicomotor (CARVALHO, 2006a), o que implicou no fato de que poucos professores visualizavam nesse aluno um potencial para o aprendizado. No entanto, com o passar do tempo, as pesquisas e a experiência diária provaram o contrário. Porém, isso só foi possível a partir do momento em que o professor se permitiu ousar e se desacomodar, quando ele compreendeu que "o ensino deve ser organizado de forma que contemple as crianças em suas distintas capacidades”. (BEYER, 2013, p. 29).

Ainda sobre esse assunto, a Professora “29” enfatiza que:

As ações do programa contribuíram no sentido de possibilitar o direcionamento de um novo olhar para estes alunos e igualmente para o grupo, com o intuito de desconstruir práticas excludentes, tornando-as práticas transformadoras que considerem o aluno como sujeito ativo no processo de aprendizagem e respeitem suas capacidades [...]. (Relato da Professora "29").

Dessa forma, quando o professor reestruturou sua prática pedagógica, passou a oportunizar, aos seus alunos, sua participação ativa nos processos que envolvem o ensinar e o aprender. Para tanto, o professor precisou modificar a organização do seu ensino, isto é, planejamento, metodologia e formas de avaliação, uma vez que o aluno que estava se apresentando na sala de aula era um aluno heterogêneo e, portanto, carecia de uma atenção especial. Esse fato fez com que o professor 
percebesse que o aluno com deficiência apresentava potencial para aprender; bastava a criação de estratégias que propiciassem a esse aluno uma participação efetiva em sua aprendizagem, trazendo à sala de aula assuntos que tivessem significado para ele, não mais um ensino repetitivo e fragmentado. Mantoan (2006, p. 192) concorda e complementa essa questão afirmando que:

[...] a inclusão é produto de uma educação plural, democrática e transgressora. Ela provoca uma crise escolar, ou melhor, uma crise de identidade institucional, que, por sua vez, abala a identidade dos professores e faz que a identidade do aluno seja ressignificada. O aluno da escola inclusiva é outro sujeito, que não tem uma identidade fixada em modelos ideais, permanentes, essenciais.

A partir dessas problematizações, a escola, como um todo, precisou organizar-se para receber o aluno com deficiência. O currículo escolar também foi repensado, assim como adaptado. Contudo, além do currículo, precisaram ser repensados os métodos, as técnicas de ensino e avaliação, as estratégias de aprendizagem e o estabelecimento de objetivos e de metas específicos para o aluno com deficiência. Sobre esse assunto, as professoras entrevistadas afirmaram que o PNAIC:

Contribuiu para o professor ver que é possível diversificar atividades que incluam os alunos com necessidades especiais, fazendo com que ele participe e se inclua nas atividades propostas. (Relato da Professora "12").

Acredito que contribuiu muito pois nos fez refletir e buscar novas possibilidades para o trabalho com estes alunos que nos desafiam e desacomodam, fazendo com que devemos adotar diferentes metodologias. (Relato da Professora "36").

A formação do PNAIC proporcionou espaço para discussões, relatos e principalmente estudos para pensar alternativas na prática pedagógica. (Relato da Professora “ 38 ”).

Diante disso, os professores reconhecem que é necessário (re)pensar alternativas para que o aluno com deficiência possa, de forma efetiva, participar dos processos de ensino e aprendizagem, ou seja, para que ele tenha igualdade de oportunidades para aprender. Stainback et al. (1999, p. 241) comentam a respeito das adaptações necessárias quando se pensa em uma educação inclusiva:

[...] nós, educadores, precisamos ter uma visão crítica do que está sendo exigido de cada aluno. Embora os objetivos educacionais básicos para todos os alunos possam continuar sendo os mesmos, os objetivos específicos da aprendizagem curricular podem precisar ser individualizados para serem adequados às necessidades, às habilidades, aos interesses e às competências singulares de cada aluno.

Partindo dessas constatações, espera-se que o professor da sala de aula regular, em conjunto com o especialista em Educação Especial, trace metas/objetivos 
de aprendizagem e planeje estratégias para que essas metas sejam alcançadas para que, assim, o aluno sinta-se incluído de fato e não apenas de direito.

A Professora "30" também trouxe um importante relato. Para ela, o PNAIC: "Reforçou a importância da diversidade de materiais, de atividades, de agrupamentos em aula e de ambientes".

Essas estratégias citadas pela Professora “30” são fundamentais para um trabalho inclusivo. O trabalho em grupo é uma excelente metodologia para o professor dinamizar suas aulas. Por meio deste tipo de trabalho, o professor oportuniza muitas trocas de conhecimento, além de estimular o respeito aos diferentes ritmos de aprendizagem. Assim, os colegas irão perceber que todos são diferentes e devem ser respeitados em suas singularidades. Carvalho (2006b, p. 32) assegura que "o trabalho individualizado e individualizante vai cedendo vez para as tarefas cooperativas".

Outro tópico que emergiu na análise das entrevistas foi a importância de se estabelecer parcerias para que a inclusão seja efetivada. Nas palavras das seguintes professoras:

Acredito ter ajudado porém para que se concretize todos os segmentos da escola devem colaborar, ainda percebe-se que nas escolas falta este comprometer-se integralmente com a educação especial. (Relato da Professora "269").

Contribuiu na questão teórica mas ainda sentimos a necessidade de que a ajuda se efetive na prática, visto que a inclusão deve se dar pelos alunos, familias e toda comunidade escolar. (Relato da Professora "25").

Após o relato das professoras, foi possível verificar que as elas sentem necessidade de apoio tanto da comunidade escolar quanto da família do aluno com deficiência. Concorda-se com os relatos das professoras, pois a inclusão não deve ser responsabilidade apenas do professor.

Nas escolas que incluem e apóiam todos os alunos, os professores, os pais, os alunos, o pessoal de apoio, os administradores, os membros da comunidade e outros estão envolvidos nas equipes de tomada de decisão ou forças-tarefa que determinam grande parte dos procedimentos e das práticas da escola. (SCHAFFNER; BUSWELL, 1999, p. 71).

Nessa perspectiva, o professor não se sente solitário, pois as tomadas de decisões são realizadas de forma conjunta. Todas as instâncias se comprometem, fazendo com que, consequentemente, haja maiores chances de uma inclusão de qualidade. Além disso, como relata a Professora "78": "[...] os professores abriram novos horizontes e conhecimentos a respeito desse assunto, estão mais flexíveis e entendendo que é um processo contínuo". 
Logo, a inclusão é um processo contínuo, ela está em constante transformação. Práticas/experiências inclusivas precisam ser socializadas para que outros professores utilizem essas experiências em suas práticas pedagógicas, adequando-as às suas realidades. Ainda, as professoras participantes da pesquisa relataram ser positivas as trocas de experiências oportunizadas nos encontros do PNAIC.

O PNAIC foi um espaço/tempo de formação que oportunizou estudos sobre as necessidades educacionais especiais, bem como criou-se momentos de relato pelas professoras para dizer o que fazem, como fazem e buscar alternativas pedagógicas para retomar o fazer em sala de aula. (Relato da Professora "41").

Nos encontros do PACTO tivemos a oportunidade de estudar algumas deficiências, discutir 'problemas' e sugerir algumas alternativas para solucionar a nossa dificuldade em trabalhar com essas crianças que merecem atenção especial. (Relato da Professora “62”).

Contribuiu para os professores repensarem suas práticas e tentar juntamente com os colegas alternativas e estratégias que os auxiliem em algumas atividades em sala de aula com os alunos com necessidades especiais. (Relato da Professora “13”).

Ademais, acredita-se que todos os alunos se beneficiam com a inclusão escolar, uma vez que o professor precisará modificar suas práticas pedagógicas em sala de aula. Com isso, o professor precisará diversificar suas estratégias de ensino, beneficiando todos os alunos e não apenas os que apresentam deficiência. O relato da Professora "102" ilustra esse fato: “[...] a partir do PACTO todas as atividades propostas foram elaboradas levando em conta as necessidades individuais dos alunos, os quais puderam participar com os demais por se tratar de aulas lúdicas, dinâmicas e interativas".

Desse modo, "o professor que ensina a turma toda não tem o falar, o copiar e o ditar como recursos didático-pedagógicos básicos. Ele partilha com seus alunos a construção/autoria dos conhecimentos produzidos em uma aula". (MANTOAN, 2008b, p. 65). Concorda-se com a autora quando ela defende que o professor precisa "aprender a ensinar a turma toda", tendo em vista que essa turma é heterogênea; portanto, o ensino precisa abranger essa heterogeneidade. Não é uma tarefa fácil, mas o professor que assume esse desafio e busca parcerias caminha para uma prática inclusiva.

Além dos relatos positivos da contribuição do PNAIC frente à prática pedagógica inclusiva, houve alguns relatos (6,05\%) de que o Programa deixou lacunas e, com isso, não contribui para sua formação. Algumas participantes relataram que:

Quanto às necessidades especiais acho que ficou falho, deveria ser mais aprofundado tanto na teoria quanto na prática também. (Relato da Professora "211").

Contribuiu muito pouco. Necessitamos de estudos profundos com sugestões de práticas para trabalhar com alunos com deficiência. (Relato da Professora "15"). 
Contribuiu muito pouco, pois deveria ter mais coisas concretas desse assunto, como lidar com essas deficiências. (Relato da Professora “19”).

Acredito que oficinas sobre tecnologias assistivas poderiam ter enriquecido a discussão. (Relato da Professora “50”).

A partir desses relatos, verificou-se que alguns professores sentiram necessidade de um maior aprofundamento do tema durante as formações do PNAIC. Considera-se positiva essa crítica, pois comprova que o professor está sentindo necessidade de discutir sobre esse assunto, de trocar experiências e de construir novas aprendizagens. Além disso, demonstra que o professor não está em uma zona de conforto, não está esperando que ingresse em sua turma um aluno com deficiência para, posteriormente, buscar uma formação que o subsidie nessa prática. A Professora "123" aborda essa questão:

Contribuiu nos mostrando alternativas para que o trabalho com crianças com necessidades educacionais especiais seja realizado com êxito. Mostrando também que devemos estudar sempre e estar preparados para receber os mesmos em nossas salas a qualquer momento. (Relato da Professora "123”).

Para ela, o PNAIC contribuiu para sua formação; todavia, ela expõe uma preocupação quanto à constante formação para se atualizar e estar subsidiada teoricamente para, depois, aplicar esses conhecimentos na prática, ou seja, para quando houver, em sua turma, um aluno deficiente.

\section{Considerações finais}

A presente pesquisa teve como propósito verificar se o PNAIC colaborou para os professores Orientadores de Estudo participantes do Programa no ano de 2013, em relação à sua formação profissional. Além disso, objetivou analisar se o Programa contribuiu para a prática pedagógica inclusiva desses professores frente aos alunos com deficiência.

Para tanto, contou-se com a participação de 347 professores Orientadores de Estudo, os quais responderam a uma entrevista estruturada. Após, as entrevistas foram analisadas qualitativamente e quantitativamente.

Em relação às contribuições do PNAIC como curso de formação continuada, os dados analisados apontam que, para 330 participantes (95,1\%), o Programa colaborou para sua formação continuada, qualificando suas práticas pedagógicas. Concluiu-se, então, que a referida pesquisa revelou que o PNAIC contribuiu significativamente para a maioria dos participantes.

Por meio dos fragmentos expostos, foi possível perceber o impacto que o PNAIC causou na forma como esses professores vêm construindo e reconstruindo seus saberes docentes, ou seja, debruçando-se nas suas experiências práticas de 
profissão. Experiências essas que foram, ao longo do programa, contribuindo para a formação dos pares e dando voz àqueles que, por muito tempo, foram silenciados.

Acredita-se que os professores das escolas atuais necessitam de formação que os instrumentalizem para que possam atender às necessidades próprias do alunado da Educação Especial. É nesse sentido que a formação continuada faz-se relevante para a atuação do professor frente aos alunos com deficiência. A formação de professores tem fundamental importância para que a inclusão seja uma prática e não um mero discurso presente em nossos espaços educacionais e sociais e nas políticas que regem as escolas brasileiras.

Quanto às contribuições do PNAIC relativas à prática pedagógica inclusiva, $257(74,06 \%)$ dos professores Orientadores de Estudo apontaram o Programa como colaborador desse processo. Nos relatos apresentados, ficou evidente que muitos professores consideraram que o PNAIC atentou à questão da inclusão escolar dos alunos com deficiência e às implicações que esse processo demanda.

Logo, percebeu-se que a inclusão escolar é um desafio que se apresenta para o professor da sala de aula regular. Porém, este desafio pode ser um fator positivo, pois instiga o professor a buscar meios para complementar sua formação inicial que, muitas vezes, não contemplou a inclusão escolar. Portanto, a partir dos dados desta pesquisa, constatou-se que o PNAIC foi um propulsor dessa formação, ainda que incipiente, e colaborou para trazer a inclusão escolar como parte do cenário da alfabetização das crianças.

Sabe-se que não há uma receita mágica que fará com que, de uma hora para outra, os alunos com deficiência sejam alfabetizados no mesmo ritmo que seus colegas sem deficiência. No entanto, formar parcerias em prol da alfabetização desses alunos já é um ponto de partida muito importante, o qual irá subsidiar todo o trabalho pedagógico do professor em sala de aula.

Para isso, o apoio do professor especialista é fundamental para o professor regular, e deverá haver uma parceria muito sólida entre eles, o que demandará, por parte de ambos, saber trabalhar em equipe, uma tarefa desafiadora, mas muito rica quando bem estruturada. Ademais, é indispensável a participação da equipe gestora, pois caberá a ela organizar o projeto pedagógico, que dará o suporte para que a escola seja realmente inclusiva. Por fim, mas não menos importante, há a família do aluno com deficiência, a qual é membro crucial para a inclusão, pois é a base de confiança e de incentivo aos alunos com deficiência. A família deve ser resgatada - seja por meio de reuniões, de grupos de estudos, de participações em conselhos, entre outras situações -, pois afastou-se da escola e, com isso, afetou diretamente a qualidade da educação de todos os alunos.

Alguns Orientadores de Estudo sentiram-se inseguros e acharam que o PNAIC não abordou de forma suficiente a inclusão escolar e as práticas pedagó- 
gicas que devem ser adotadas nesse processo. Portanto, esse é um dos desafios dos Programas de Formação de Professores: suprir as diferentes carências que apresentam seus participantes. Colaborar para a formação continuada destes professores é fundamental, mas sempre ficarão lacunas a serem preenchidas, e caberá ao próprio professor continuar nessa busca incessante por aprimorar seus conhecimentos, afinal o conhecimento nunca se esgota.

Por fim, a partir da pesquisa realizada, concluiu-se que o PNAIC contribuiu para a formação continuada dos professores e trouxe, para o centro do debate, a alfabetização dos alunos com deficiência. O Programa motivou os Orientadores de Estudo a conhecer/pesquisar ainda mais sobre os processos que estão envolvidos durante a contínua busca pela qualidade da inclusão escolar.

\section{Referências}

ALENCAR, E. S.; FLEITH, D. de S. Superdotados: determinantes, educação e ajustamento. 2. ed. São Paulo: EPU, 2001.

BEYER, H. O. A primeira condição: individualização do ensino. In: BEYER, H. O. Inclusão e avaliação na escola de alunos com necessidades educacionais especiais. Porto Alegre: Mediação, 2013. p. 28-31.

BIANCHETTI, L. Aspectos históricos da apreensão e da educação dos considerados deficientes. In: BIANCHETTI, L.; FREIRE, I. M. (Orgs.). Um olhar sobre a diferença: interação, trabalho e cidadania. São Paulo: Papirus, 1998. p. 21-51.

BRASIL. Constituição da República Federativa do Brasil: promulgada em 5 de outubro de 1988. Disponível em: <http://www.planalto.gov.br/ccivil_03/constituicao/ constituicaocompilado.htm> Acesso em: 06 jan. 2015.

BRASIL. Ministério da Educação e do Desporto. LDB - Lei no 9394/96, de 20 de dezembro de 1996. Estabelece as diretrizes e bases da Educação Nacional. Brasília: MEC, 1996.

BRASIL. Diretrizes Nacionais para a Educação Especial na Educação Básica. Brasília: MEC/SEESP, 2001.

BRASIL. Programa educação inclusiva: direito à diversidade. A fundamentação Filosófica. Brasília: MEC/SEESP, 2004.

BRASIL. Secretaria de Educação Especial. Política Nacional de Educação Especial na Perspectiva da Educação Inclusiva. Brasília: MEC/SEESP, 2008.

BRASIL. Ministério da Educação. Secretaria de Educação Básica. Diretoria de Apoio à Gestão Educacional. Pacto Nacional pela Alfabetização na Idade Certa: formação de professor alfabetizador: Caderno de apresentação. Brasília: MEC/SEB, 2012.

BRASIL. Ministério da Educação. Secretaria de Educação Básica. Diretoria de Apoio à Gestão Educacional. Pacto Nacional pela Alfabetização na Idade Certa: Educação Inclusiva. Brasília: MEC/SEB, 2014.

CARVALHO, R. E. Educação inclusiva: alguns aspectos para a reflexão. In: CARVALHO, R.

E. Educação Inclusiva: com os pingos nos “is”. Porto Alegre: Mediação, 2006a. p. 64-74. 
CARVALHO, R. E. Correntes teóricas e sua influência no processo educacional. In: CARVALHO, R. E. Educação Inclusiva: com os pingos nos “is”. Porto Alegre: Mediação, 2006b. p. 19-32.

FREIRE, P. Pedagogia da autonomia. Saberes necessários à prática educativa. São Paulo: Paz e Terra, 1996.

FREITAS, S. N.; RECH, A. J. D. Atividades de enriquecimento escolar como estratégia para contribuir com a inclusão escolar dos alunos com altas habilidades/superdotação. Arquivos Analíticos de Políticas Educativas, v. 23, n. 30, p. 1-17, mar. 2015. (Dossiê Educação Especial: Diferenças, Currículo e Processos de Ensino e Aprendizagem II). DOI: 0.14507/epaa.v23.1639

IMBERNÓN, F. Formação continuada de professores. Tradução de Juliana dos Santos Padilha. Porto Alegre: Artmed, 2010.

LIMA, S. M. de. Aprender para ensinar, ensinar para aprender: um estudo do processo de aprendizagem profissional da docência de alunos-já-professores. 2003. 321 f. Tese (Doutorado em Educação) - Universidade Federal de São Carlos, São Carlos, 2003.

MANTOAN, M. T. E. O direito de ser, sendo diferente, na escola. In: RODRIGUES, D. (Org.). Inclusão e educação: doze olhares sobre a educação inclusiva. São Paulo: Summus, 2006. p. 183-209.

MANTOAN, M. T. E. Inclusão escolar: caminhos, descaminhos, desafios, perspectivas. In: MANTOAN, M. T. E. O desafio das diferenças nas escolas. Petrópolis, Rio de Janeiro: Vozes, 2008a. p. 29-41.

MANTOAN, M. T. E. Ensinando a turma toda: as diferenças na escola. In: MANTOAN, M. T. E. O desafio das diferenças nas escolas. Petrópolis, Rio de Janeiro: Vozes, 2008b. p. 59-67.

NASCIMENTO, R. P. do. Preparando professores para promover a inclusão de alunos com necessidades educacionais especiais. 2009. Disponível em: <http://www.diaadiaeducacao. pr.gov.br/portals/pde/arquivos/2496-8.pdf>. Acesso em: 27 jan. 2015.

NEUBAUER, B. M.; SILVA, P. S. da; RISTOW, S. Z.; ROSA, V. S. da. Formação continuada de professores: a construção dos saberes experienciais. In: ANTUNES, H. S. (Org.). Trajetória docente: o encontro da teoria com a prática. Santa Maria: Universidade Federal de Santa Maria, Centro de Educação, Departamento de Metodologia do Ensino, 2005. p. 61-68.

OLIVEIRA, V. F. Formação docente: aprendizagens e significações imaginárias no espaço grupal. Revista Brasileira de Pesquisa sobre Formação Docente, Belo Horizonte, v. 2, n. 2, p. 68-82, jan/jul. 2010.

SASSAKI, R. K. Inclusão. Construindo uma sociedade para todos. Rio de Janeiro: WVA, 1997.

SCHAFFNER, C. B.; BUSWELL, B. E. Dez elementos críticos para a criação de comunidades de ensino inclusivo e eficaz. In: STAINBACK, S.; STAINBACK, W. (Orgs.). Inclusão: um guia para educadores. Porto Alegre: Artmed, 1999. p. 69-87.

STAINBACK, W.; STAINBACK, S.; STEFANICH, G.; ALPER, S. A aprendizagem nas escolas inclusivas: e o currículo? In: STAINBACK, W.; STAINBACK, S. (Orgs.). Inclusão: um guia para educadores. Porto Alegre: Artmed, 1999. p. 240-251.

UNESCO. Organização das Nações Unidas para a Educação, a Ciência e a Cultura. Declaração mundial sobre educação para todos: satisfação das necessidades básicas de aprendizagem. Jomtien, 1990. Disponível em: < http://www.unicef.org/brazil/pt/resources_10230.htm>. Acesso em: 27 jan. 2015. 
UNESCO. Organização das Nações Unidas para a Educação, a Ciência e a Cultura. Declaração de Salamanca: sobre princípios, políticas e práticas na área das necessidades educativas especiais. Salamanca, Espanha, 1994. Disponível em: < http://portal.mec.gov.br/seesp/arquivos/pdf/ salamanca.pdf $>$. Acesso em: 22 jan. 2015.

UFMS. Universidade Federal de Mato Grosso do Sul. Pró-Reitoria de Ensino de Graduação. Coordenadoria de Educação Aberta e a Distância. Educação Especial. Campo Grande, 2004. (CD-ROM).

Recebido em 30/11/2014

Aceito em 05/07/2015 